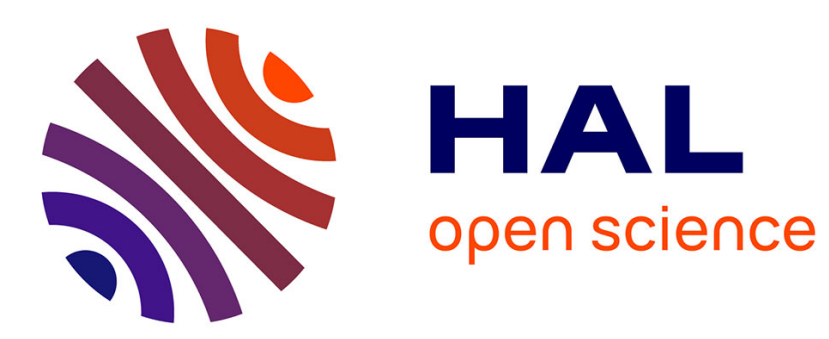

\title{
Hot Ductility and High Temperature Microstructure of High Purity Iron Alloys
}

\author{
K. Abiko
}

\section{To cite this version:}

K. Abiko. Hot Ductility and High Temperature Microstructure of High Purity Iron Alloys. Journal de Physique IV Proceedings, 1995, 05 (C7), pp.C7-77-C7-84. 10.1051/jp4:1995706 . jpa-00253999

\section{HAL Id: jpa-00253999 https://hal.science/jpa-00253999}

Submitted on 1 Jan 1995

HAL is a multi-disciplinary open access archive for the deposit and dissemination of scientific research documents, whether they are published or not. The documents may come from teaching and research institutions in France or abroad, or from public or private research centers.
L'archive ouverte pluridisciplinaire HAL, est destinée au dépôt et à la diffusion de documents scientifiques de niveau recherche, publiés ou non, émanant des établissements d'enseignement et de recherche français ou étrangers, des laboratoires publics ou privés. 


\title{
Hot Ductility and High Temperature Microstructure of High Purity Iron Alloys
}

K. Abiko

Institute for Materials Research, Tohoku University, Sendai 980-77, Japan

\begin{abstract}
The inherent properties of metals are affected by impurity elements, sometimes strongly. There are many brittle phenomena in iron and its alloys due to the harmful effect of trace impurities such as sulphur, phosphorus, hydrogen and so on. On the other hand, a large number of alloying elements also embrittle iron due to the transformation and precipitation of secondary phase. For example, the ductility of $\mathrm{Fe}-\mathrm{Cr}$ alloy decreases with the increase in chromium content, although the strength and the corrosion resistance increase with chromium content. In $\mathrm{Fe}-\mathrm{Cr}$ alloy containing high chromium, $475^{\circ} \mathrm{C}$ embrittlement and $\sigma$-phase embrittlement are well known. An Fe-50mass\% $\mathrm{Cr}$ alloy of conventional purity is extremely brittle due to the formation of $\sigma$-phase. However, we found the highly purified alloy is essentially ductile. In the workshop of UHPM-94, the experimental results on the ductility of $\mathrm{Fe}-50$ mass $\% \mathrm{Cr}$ alloy were presented and discussed. In this research, the effect of purification on the hot ductility of high purity $\mathrm{Fe}-18 \mathrm{mass} \% \mathrm{Cr}$ and $\mathrm{Fe}-50 \mathrm{mass} \% \mathrm{Cr}$ alloys was investigated by tensile testing at high temperature. It was found that the ductility of $\mathrm{Fe}-18 \mathrm{mass} \% \mathrm{Cr}$ alloy is remarkably improved by purification, especially by the reduction of interstitial impurities such as carbon and nitrogen. The highlypurified $\mathrm{Fe}-50$ mass $\% \mathrm{Cr}$ alloy has astonishing ductility at the temperature range between room temperature and $1073 \mathrm{~K}$. Also in a high purity $\mathrm{Fe}-50$ mass $\% \mathrm{Cr}$ alloy, the formation of the $\sigma$-phase was not observed during ageing for $1000 \mathrm{~h}$ at $973 \mathrm{~K}$. These results are also very important for the development of high-performance $\mathrm{Fe}-\mathrm{Cr}$ alloys and of the manufacturing process. Consequently, purification technology is very useful for progress in metal science.
\end{abstract}

Keywords: Fe-Cr alloy, $\sigma$-phase, Mechanical Properties, Hot ductility, Serration, Work hardening, High temperature strength, Dynamic recrystallization.

\section{INTRODUCTION}

It is very important for progress in metal science and the development of base metals that the inherent properties of metals, and the intrinsic effect of impurity elements and alloying elements on the properties, should be clarified [1].

There are many brittle phenomena in iron and its alloys due to the effect of harmful impurity elements such as sulphur, phosphorus, hydrogen and so on. For example, phosphorus and sulphur in iron and alloys reduce the cohesion of grain boundaries at near room temperature [2]. Temper embrittlement caused by the segregation of harmful impurities such as phosphorus, antimony and tin at grain boundaries is a serious problem in high strength, low alloyed steels [3].

The hot ductility of iron is also affected by impurity elements. Sulphur reduces the hot ductility of iron at temperatures between 873 and $1073 \mathrm{~K}$ in tensile tests [4]. On the other hand, phosphorus increases the hot ductility of iron and steel above $773 \mathrm{~K}[5,6]$.

Many alloying elements also affect the ductility of metals strongly. In the extreme case, the intermetallic compound is well known to be very strong, but brittle. These properties may be caused by strong bonding between compositional elements, and decohesion between impurities and compositional elements. In the case of a solid solution containing a large quantity of alloying elements such as Fe-Cr stainless steel, ductility decreases with the increase in chromium content. Interstitial impurities such as carbon and nitrogen enhance the work hardening of $\mathrm{Fe}-\mathrm{Cr}$ alloys $[7,8]$. In other words, the ductility of $\mathrm{Fe}-\mathrm{Cr}$ alloys is improved by purification, especially by the removal of interstitial impurities. $475^{\circ} \mathrm{C}$ embrittlement and $\sigma$-phase embrittlement in $\mathrm{Fe}-\mathrm{Cr}$ alloy containing high chromium are well known. 
In the workshop of UHPM-94, the experimental results on the ductility of Fe-50mass\% Cr alloy were presented and discussed [9]. An Fe-50mass\% Cr alloy of conventional purity is well known to be extremely brittle due to the formation of $\sigma$-phase. However, we found the highly-purified alloy is essentially ductile. Furthermore, in the highly-purified alloy, no $\sigma$-phase is observed after annealing at high temperature. Though this is an astonishing phenomenon resulting from the purification of the alloy, it is significant for progress in metal science and the development of high-performance metallic materials.

In this research, the inherent mechanical properties of Fe-18mass\% $\mathrm{Cr}$ and $\mathrm{Fe}-50 \mathrm{mass} \% \mathrm{Cr}$ alloys, and the effect of purification on their hot ductility were investigated by tensile tests at high temperature. The recrystallization behaviour and the formation of $\sigma$-phase were also investigated by optical microscope observation .

\section{EXPERIMENTAL PROCEDURES}

Two kinds of high purity $\mathrm{Fe}-\mathrm{Cr}$ alloys, $\mathrm{Fe}-18$ mass $\% \mathrm{Cr}$ and $\mathrm{Fe}-50$ mass $\% \mathrm{Cr}$, were melted by different techniques for the present research. High purity electrolytic iron and high purity chromium were used as the starting materials for these alloys [10]. The mechanical properties of high purity $\mathrm{Fe}-\mathrm{Cr}$ alloys at high temperature were investigated by tensile testing. The microstructure was observed by optical microscope in order to investigate the static and dynamic recrystallization behaviour .

\section{2-1 High Purity Fe-18mass\% Cr Alloy}

An ingot of a high purity $\mathrm{Fe}-18 \mathrm{mass} \% \mathrm{Cr}$ alloy was melted in a crucible lined with high purity $\mathrm{CaO}$. The chemical compositions of the starting materials and the melted $\mathrm{Fe}-18$ mass $\% \mathrm{Cr}$ alloy(HP) were analyzed as shown in Table 1 . The ingot was heated at $1273 \mathrm{~K}$ in a high purity Ar atmosphere, then forged and rolled to rods of $6.5 \mathrm{~mm}$ in diameter. The specimens for tensile testing were made from the rods by machining. The gauge length and diameter of specimens are $20.0 \mathrm{~mm}$ and $3.00 \mathrm{~mm}$, respectively. The static recrystallization behaviour of a high purity $\mathrm{Fe}-18 \mathrm{mass} \backslash \% \mathrm{Cr}$ alloy after $85 \%$ reduction by cold rolling was investigated. Every tensile specimen was heat-treated for $10 \mathrm{~min}$ at $1213 \mathrm{~K}$ and quenched in oil at $273 \mathrm{~K}$. The grain size of heat-treated specimens was $30 \mu \mathrm{m}$ on average. The tensile tests on the high purity $\mathrm{Fe}-18 \mathrm{mass} \% \mathrm{Cr}$ alloy were mainly performed at a strain rate of $3.9 \times 10^{-5} / \mathrm{sec}$, at temperatures between $293 \mathrm{~K}$ and $873 \mathrm{~K}$, and in a vacuum better than $5 \times 10^{-6}$ torr.

\begin{tabular}{|l|c|c|c|c|c|c|c|c|c|c|}
\hline element & $\mathrm{Cr}$ & $\mathrm{C}$ & $\mathrm{N}$ & $\mathrm{O}$ & $\mathrm{S}$ & $\mathrm{P}$ & $\mathrm{Al}$ & $\mathrm{Si}$ & $\mathrm{Ni}$ & $\mathrm{Mn}$ \\
\hline High purity electrolytic iron & 0.0001 & 15 & 3 & 53 & 11 & 0.3 & 0.1 & 2 & $<0.1$ & $<0.01$ \\
\hline High purity chromium & 99.8 & 70 & 40 & 130 & 3 & 10 & 10 & 50 & 10 & 20 \\
\hline High purity alloy(HP) & 18.0 & 91 & 4 & 15 & 7 & 2 & 3 & $<1$ & 2 & 2 \\
\hline & (mass\%) & \multicolumn{7}{|c|}{ (massppm) } \\
\hline
\end{tabular}

Table 1 The chemical compositions of starting materials and the melted $\mathrm{Fe}-18$ mass\%Cr alloy (HP).

\section{2-2 Zone Refined Fe-18mass \% Cr Alloy}

The Fe-18mass \%Cr rods of $10 \mathrm{~mm}$ in diameter were specially purified by the zone refining method in high purity hydrogen flow, in order to obtain a tensile specimen with ultra-low interstitial impurities. The content in carbon, nitrogen and oxygen was analyzed for zone refined alloys(FZ1 and FZ2) as shown in Table 2. The purified rods with different carbon contents were cold-swaged to rods of $6.5 \mathrm{~mm}$ in diameter, and then tensile specimens were machined from the rods. These specimens were heat-treated in a vacuum for $15 \mathrm{~min}$ at $1023 \mathrm{~K}$ and quenched in oil at $273 \mathrm{~K}$. The tensile specimen of a high purity Fe18 mass \% Cr(HP) alloy was also heat-treated under the same conditions. The grain sizes of HP and FZ2 after the heat treatment were $75 \mu \mathrm{m}$ and $65 \mu \mathrm{m}$ on average, respectively. Tensile testing of these alloys was carried out under the same conditions as mentioned above. 


\begin{tabular}{|c|r|c|c|c|}
\hline alloy & C & N & O & S \\
\hline FZ1 & 35 & 2 & 1 & 1 \\
\hline FZ2 & 3 & 1 & 1 & 3 \\
\hline
\end{tabular}

(massppm)

Table 2 The contents of carbon, nitrogen and oxygen were analyzed for zone refined alloys(FZ1 and FZ2).

\section{2-3 High Purity Fe-50mass\% Cr Alloy}

An ingot of $\mathrm{Fe}-50$ mass\% $\mathrm{Cr}$ alloy was melted in a cold crucible made of copper. The chemical compositions of the starting materials and the melted $\mathrm{Fe}-50$ mass $\% \mathrm{Cr}$ alloy were analyzed as shown in Table 3. The ingot was heated at $1323 \mathrm{~K}$ in high a purity Ar atmosphere, forged and rolled to rods of $6.5 \mathrm{~mm}$ in diameter. The specimens for tensile testing were made with the same process as for the high purity Fe-18mass\% Cr alloy.

\begin{tabular}{|l|c|c|c|c|c|c|c|c|c|}
\hline element & $\mathrm{C}$ & $\mathrm{N}$ & $\mathrm{O}$ & $\mathrm{S}$ & $\mathrm{P}$ & $\mathrm{Si}$ & $\mathrm{Mn}$ & $\mathrm{Al}$ & $\mathrm{B}$ \\
\hline Iron & 1.5 & 0.7 & 23 & 1.5 & 0.7 & 5 & $<0.01$ & 0.3 & 0.1 \\
\hline Chromium & 11 & 31 & 34 & 3 & 3 & 11 & 8 & 10 & $<0.05$ \\
\hline $\mathrm{Fe}-50 \% \mathrm{Cr}$ & 8.2 & 13 & 71 & 4.4 & 6 & 9 & 3.9 & 1.9 & 0.28 \\
\hline
\end{tabular}

(massppm)

Table 3 The chemical compositions of starting materials and the melted $\mathrm{Fe}-50$ mass\% $\mathrm{Cr}$ alloy.

Every tensile specimen was pre-heated for $60 \mathrm{~min}$ at $1373 \mathrm{~K}$ and quenched in oil at $273 \mathrm{~K}$, and then heated for $60 \mathrm{~min}$ at $1123 \mathrm{~K}$ and quenched in oil at $273 \mathrm{~K}$. The grain size of heat-treated specimen was about $100 \mu \mathrm{m}$ on average. Tensile testing for the high purity $\mathrm{Fe}-50 \mathrm{mass} \% \mathrm{Cr}$ alloy was performed under the following conditions : at a strain rate of $4.15 \times 10^{-5} / \mathrm{sec}$, at a temperature between $293 \mathrm{~K}$ and $1073 \mathrm{~K}$, and in a vacuum better than $5 \times 10^{-6}$ torr

Furthermore, the effect of tungsten on solid solution hardening at high temperature and the hot ductility of a high purity $\mathrm{Fe}-50$ mass $\% \mathrm{Cr}$ alloy were investigated by tensile test.

\section{RESULTS AND DISCUSSION}

\section{3-1 Hot Ductility of High Purity Fe-18mass\% Cr Alloy}

The stress-strain curves of a high purity $\mathrm{Fe}-18 \mathrm{mass} \% \mathrm{Cr}$ alloy(HP) with $91 \mathrm{massppm}$ carbon at various temperatures are shown in Fig.1. The strain rate is $3.9 \times 10^{-5} / \mathrm{sec}$. A sharp yield drop is observed in the stress-strain curves at the temperature between $293 \mathrm{~K}$ and $773 \mathrm{~K}$. The stress-strain curve at $873 \mathrm{~K}$ shows the shape of dynamic recrystallization during tensile test. Serration is observed in the stress-strain curves at the temperature range between $473 \mathrm{~K}$ and $773 \mathrm{~K}$. According to the degree of serration, the work hardening rate and the ultimate tensile strength increase, but the elongation decreases. The elongation of a high purity $\mathrm{Fe}-$ $18 \mathrm{mass} \% \mathrm{Cr}$ alloy shows a minimum value at the temperature of $823 \mathrm{~K}$. Elongation at temperatures above $873 \mathrm{~K}$ is more than $50 \%$. On the other hand, the reduction in area of every specimen after tensile testing is more than $80 \%$ at temperatures between $293 \mathrm{~K}$ and $873 \mathrm{~K}$.

It is well-known in $\mathrm{Fe}-\mathrm{C}$ and Fe-N alloys that serration is caused by the interaction between interstitial impurities and movable dislocations [11-13]. Cottrell reported in the investigation on strain-ageing of Fe-N alloy that the activation energy for serration is equal to the activation energy of diffusion of interstitial impurities [14]. Keh et al. reported the same relation in the study on strain-ageing of plain carbon steel [15]. 
In order to confirm the mechanism of serration in a high purity $\mathrm{Fe}-18 \mathrm{mass} \% \mathrm{Cr}$ alloy, tensile tests were carried out with different strain rates. When the strain rate increases, the degree of the serration decreases. Then no serration is observed above some strain rates at different temperatures. By the relation between the temperature of the tensile test and the strain rate at which serration occurs as shown in Fig.2, the activation energy for serration is found to be $27.8 \mathrm{Kcal} / \mathrm{mol}$. This value should be the activation energy for the diffusion of carbon in Fe-18mass\%Cr alloy after the Cottrell model.

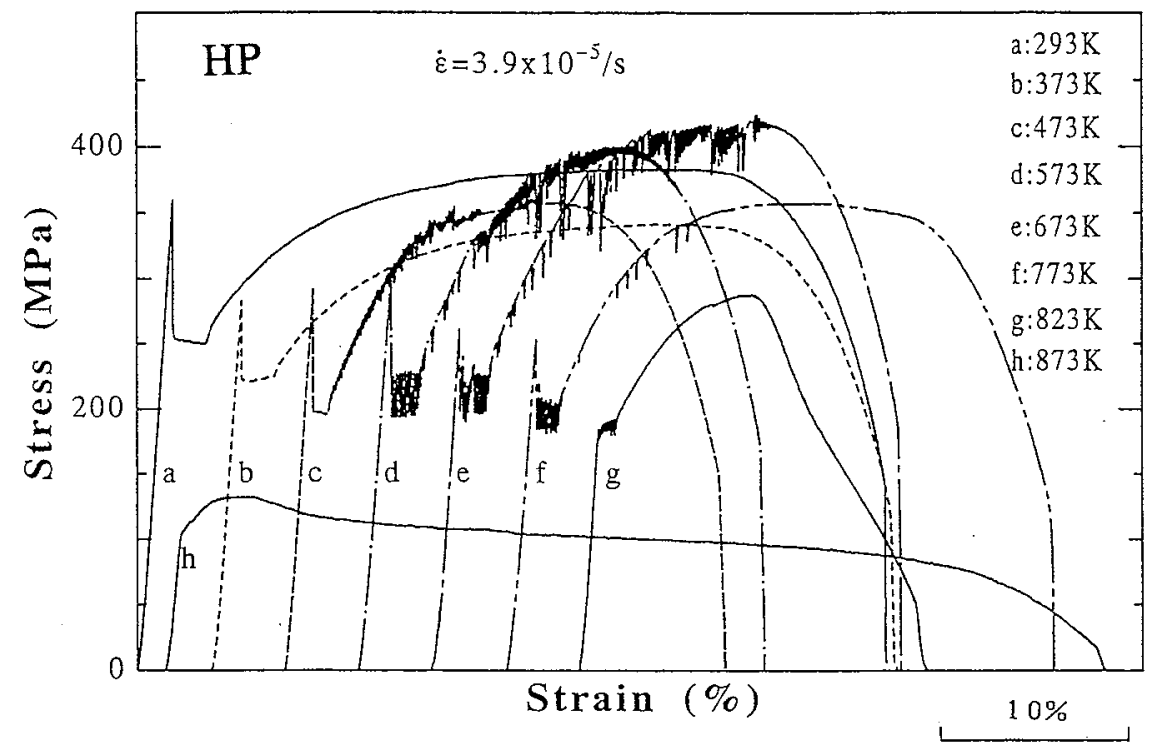

Figure 1 Stress-strain curves of a high purity $\mathrm{Fe}-18$ mass $\% \mathrm{Cr}$ alloy(HP) at various temperatures.

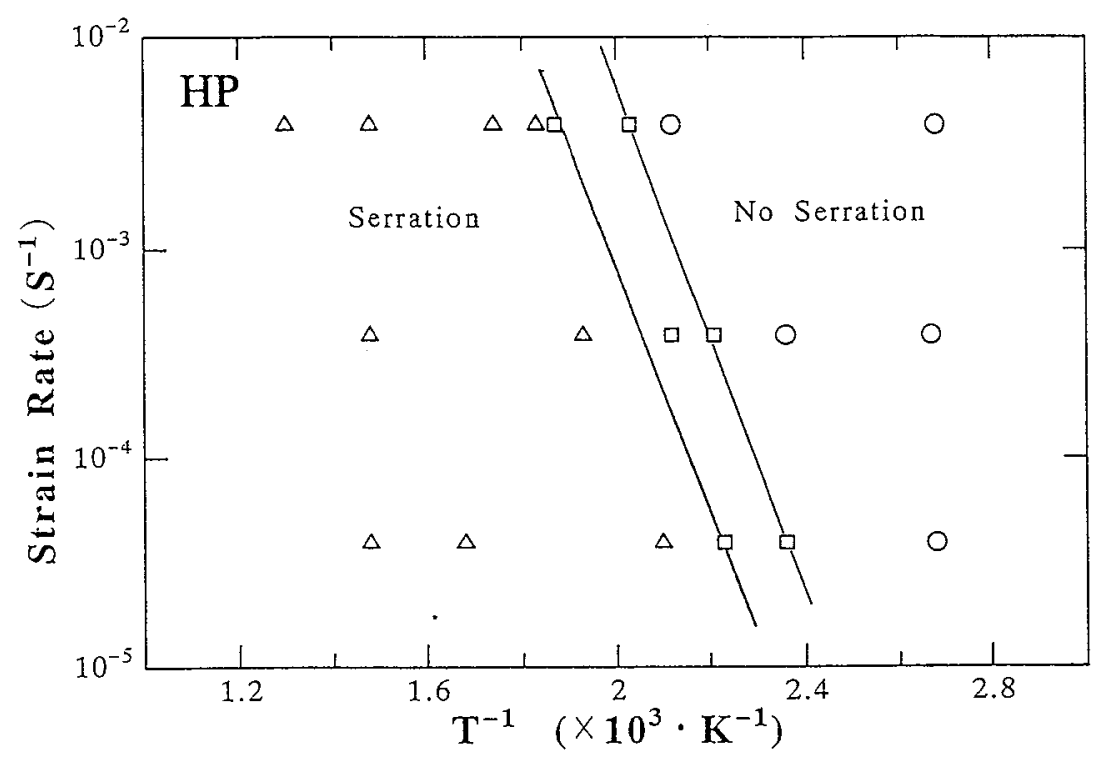

Figure 2 Relation between the temperature of tensile test and the strain rate at which serration occurs.

\section{3-2 Hot Ductility of Zone Refined Fe-18mass\% Cr Alloy}

The zone refining treatment for $\mathrm{Fe}-18 \mathrm{mass} \% \mathrm{Cr}$ alloy was performed in high purity hydrogen, in order to clarify the mechanism on the serration of $\mathrm{Fe}-\mathrm{Cr}$ alloy and the intrinsic effect of carbon on the mechanical 
properties. Table 2 shows the contents of interstitial impurities in a high purity $\mathrm{Fe}-18 \mathrm{mass} \% \mathrm{Cr}$ alloy and zone refined $\mathrm{Fe}-18$ mass\% $\mathrm{Cr}$ alloys. Figures 3 and 4 show the stress-strain curves of $\mathrm{HP}, \mathrm{FZ1}$ and FZ2 at $293 \mathrm{~K}$ and $673 \mathrm{~K}$, respectively. The proof stress, the tensile strength and the work hardening rate decrease strongly with the decrease in interstitial impurities. Ductility increases remarkably after the removal of carbon and nitrogen. For example, the elongation of FZ1 and FZ2 at $293 \mathrm{~K}$ and $673 \mathrm{~K}$ increases more than $10 \%$ from that of HP.

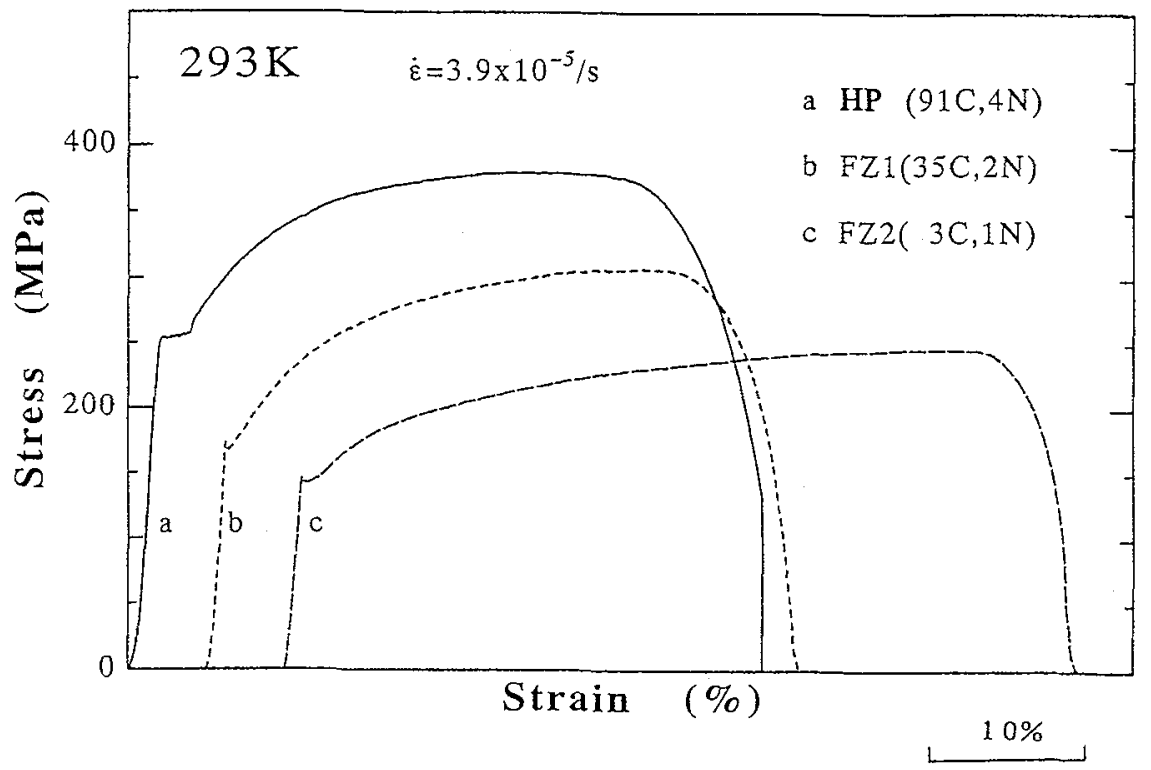

Figure 3 Stress-strain curves of 91(HP), 35(FZ1) and 3(FZ2) massppm at 293K.

It is confirmed that the degree of serration and work hardening are strongly affected by the amount of interstitial impurities, especially the amount of carbon in this case. These results are very important for the development of high-performance $\mathrm{Fe}-\mathrm{Cr}$ alloys and of the manufacturing process.

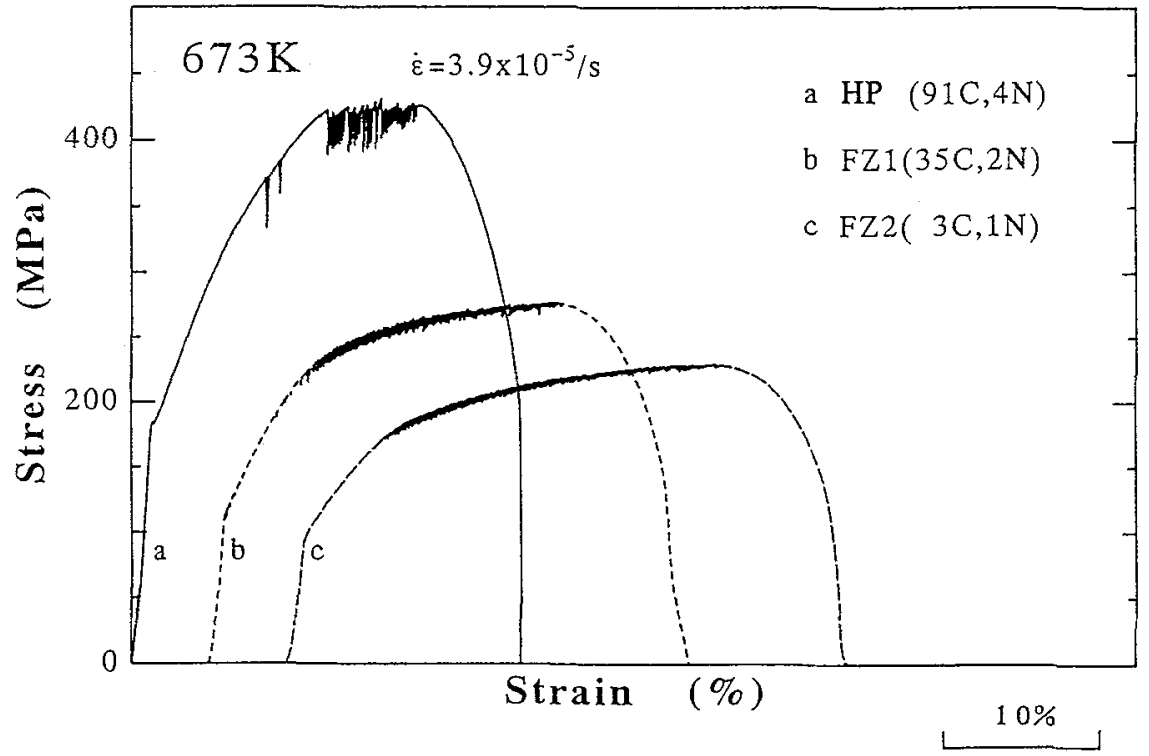

Figure 4 Stress-strain curves of 91(HP), 35(FZ1) and 3(FZ2) massppm at 673K. 


\section{3-3 Hot Ductility of High Purity Fe-50mass\% Cr Alloy}

The ductility of $\mathrm{Fe}-\mathrm{Cr}$ alloys is remarkably improved by purification, especially by the removal of interstitial impurities as mentioned above. In $\mathrm{Fe}-\mathrm{Cr}$ alloy containing more than 35 mass\% chromium, $475^{\circ} \mathrm{C} \mathrm{embrittlement} \mathrm{and} \sigma$-phase embrittlement appear.

In the workshop of UHPM-94, we briefly presented the ductility of a high purity $\mathrm{Fe}-50 \mathrm{mass} \% \mathrm{Cr}$ alloy [9]. An Fe-50mass\% $\mathrm{Cr}$ alloy of conventional purity is extremely brittle due to the formation of the $\sigma$ phase. However, we found that the highly-purified $\mathrm{Fe}-50$ mass\% $\mathrm{Cr}$ alloy is ductile enough for forging and rolling at elevated temperatures, and also for cold rolling at room temperature. Figure 5 shows, for example, the seamless tubing of the alloy which was deformed from the bar at $1573 \mathrm{~K}$.

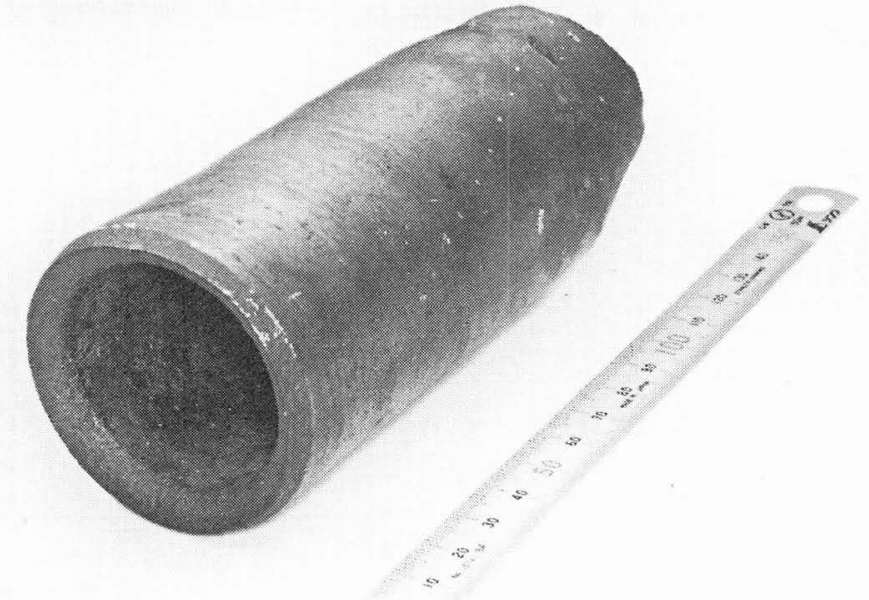

Figure 5 Seamless tubing of a high purity $\mathrm{Fe}-50$ mass $\% \mathrm{Cr}$ alloy deformed from the bar at $1573 \mathrm{~K}$.

The formation of the $\sigma$-phase is the key to the improvement of hot ductility in an $\mathrm{Fe}-50$ mass\% $\% \mathrm{Cr}$ alloy. The microstructure of a high purity $\mathrm{Fe}-50 \mathrm{mass} \% \mathrm{Cr}$ alloy was therefore observed after ageing for various periods at elevated temperatures. Also, the static recrystallization behaviour of the cold rolled alloy was investigated, because the strain may enhance nucleation of the $\sigma$-phase. Figure 6 shows one example of the microstructure after ageing for $1000 \mathrm{~h}$ at $973 \mathrm{~K}$ in a vacuum. Many points in Fig. 6 are etching pits. Consequently, no $\sigma$-phase was observed under these ageing conditions.

Figure 7 shows the stress-strain curves of a high purity $\mathrm{Fe}-50$ mass $\% \mathrm{Cr}$ alloy at various temperatures. A small yield drop is observed in the stress-strain curves at temperatures between $293 \mathrm{~K}$ and $573 \mathrm{~K}$. Slight serration in the stress-strain curves is observed at the temperature range between $573 \mathrm{~K}$ and $673 \mathrm{~K}$. On the other hand, a large serration, which seems to be twin deformation, appears between $723 \mathrm{~K}$ and $823 \mathrm{~K}$. According to the degree of the large serration, the work hardening rate and the ultimate tensile strength increase, but the elongation decreases. The elongation of a high purity $\mathrm{Fe}-50 \mathrm{mass} \% \mathrm{Cr}$ alloy reaches a minimum value at the temperature of $773 \mathrm{~K}$. However, the elongation at the temperature of $1073 \mathrm{~K}$ is more than $120 \%$. At tensile test temperatures above $873 \mathrm{~K}$, dynamic recrystallization may occur suddenly after the elastic region.

Furthermore, we investigated the effect of tungsten on the solid solution hardening at high temperatures and the hot ductility of a high purity $\mathrm{Fe}-50 \mathrm{mass} \% \mathrm{Cr}$ alloy. Tungsten suppresses dynamic recrystallization. The increment of the tensile strength by the addition of $8 \mathrm{mass} \% \mathrm{~W}$ is $80 \mathrm{MPa}$ at $1073 \mathrm{~K}$ due to the solid solution hardening of the tungsten. Surprisingly, elongation and reduction in area at $1073 \mathrm{~K}$ are improved by the addition of tungsten. 
Why does the $\sigma$-phase nucleate easily in an $\mathrm{Fe}-50 \mathrm{mass} \% \mathrm{Cr}$ alloy of conventional purity? What is the difference in compositional effects in the conventional alloy and the high purity alloy? This is of great interest in the mechanism of nucleation of the $\sigma$-phase, and the intrinsic effect of impurities and alloying elements such as tungsten on the high temperature strength and hot ductility of an Fe-50mass\% $\%$ r alloy.

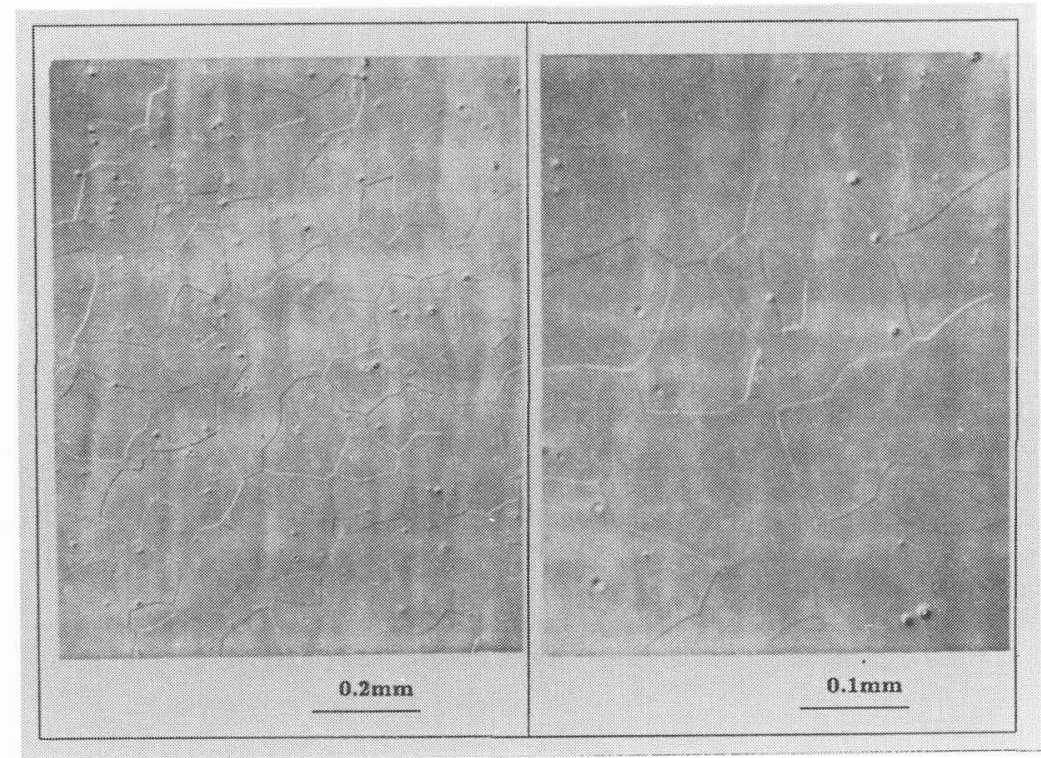

Figure 6 Microstructure of a high purity $\mathrm{Fe}-50$ mass $\% \mathrm{Cr}$ alloy after ageing for $1000 \mathrm{~h}$ at $973 \mathrm{~K}$ in the vacuum.

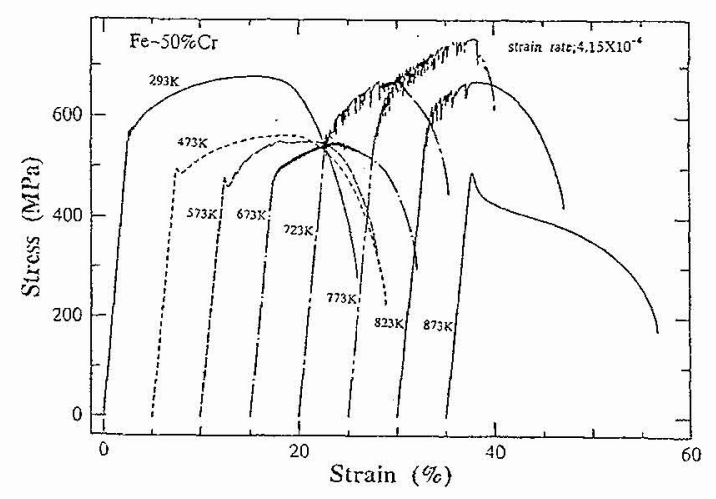

(a)

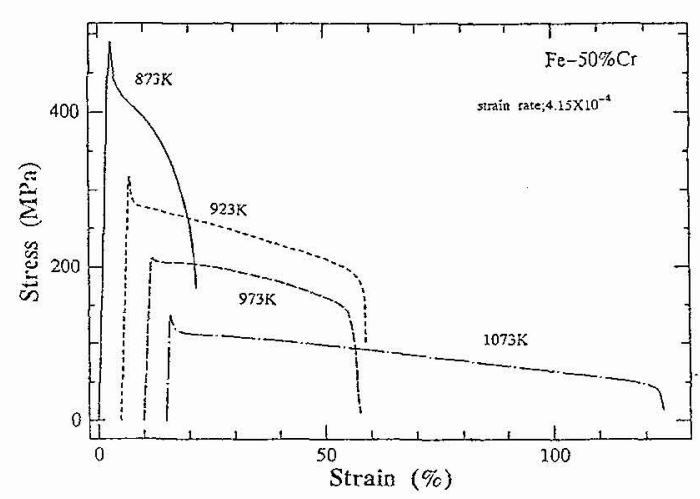

(b)

Figure 7 Stress-strain curves of a high purity $\mathrm{Fe}-50 \mathrm{mass} \% \mathrm{Cr}$ alloy at various temperatures.

\section{CONCLUSION}

Ductile Fe-Cr alloy containing high chromium will be used as a heat resistant material in many fields of industry in the near future. However, without further fundamental investigation of high purity Fe-Cr alloy, we cannot expect great advances in metallic materials for high temperature service in modern heavy industry.

It is absolutely necessary to establish a new metal science for the discovery of high-performance base metals with desirable properties corresponding to the demands of the age. We conclude that the following investigations into ultra-high purity base metals will offer a new direction for progress in metal science. 
(1) preparation of ultra-high purity base metals,

(2) analysis of very small amounts of impurity elements in purified base metals,

(3) clarification of the inherent physical and chemical properties of purified base metals, leading to the creation of a database,

(4) creation of new equipment for research on purified base metals.

I hope for further advances in materials science by ultra-high purification technology at UHPM-96.

\section{REFERENCE}

[1] Ultra High Purity Base Metals, Proceedings of The First International Conference on Ultra High Purity Base Metals (UHPM-94), May 24-27th, 1994, at Kitakyushu-City, Japan, Edited by K. Abiko, K. Hirokawa and S. Takaki, Published by The Japan Institute of Metals.

[2] K. Abiko: ibid. , p. 1.

[3] C. J. McMahon: ibid. , p. 352.

[4] C. M. Liu, T. Iyama, H. Suenaga, K. Abiko and M. Tanino: ibid. , p. 500.

[5] K. Abiko, R. L. Bodnar and D. P. Pope: Ductility and Toughness Considerations in Elevates Temperature Service, Edited by G. V. Smith, ASME, New York, 1979, pp. 1.

[6] K. Abiko, C. M. Liu, M. Ichikawa and M. Tanino: to be published in Proceedings of The Second International Conference on Ultra High Purity Base Metals (UHPM-95), June 10-16th, 1995, at Saint-Etienne, France.

[7] K. Akiyama: Master Thesis of Tohoku University, (1992).

[8] K. Abiko, S. Takaki, C. M. Liu and M. Tanino: Inherent Properties of High Purity Fe-Cr Alloys, published by ISIJ, (1994), p. 138.

[9] K. Abiko: Ultra High Purity Base Metals, (1994), p. 522.

[10] T. Daicho, N. Arisawa and K. Abiko: ibid. , p. 397.

[11] F. R. N. Nabarro: Report on Strength of Solids, Physical Society, London, (1948), p. 38.

[12] J. Friedel: Dislocation, Pergamon, (1964), p. 411.

[13] B. A. Wilcox, G. C. Smith: Acta Met. , 12 (1964), p. 371.

[14] A. H. Cottrell: Phil. Mag. 74 (1953), p. 829.

[15] A. S. Keh, Y. Nakada, and W. C. Leslie: Dislocation Dynamics, McGraw-Hill,(1968), p. 381. 